\title{
Can a Posttraumatic Stress Disorder Be Caused by a Traumatic Injury to a Companion Pet?
}

\author{
Nadine Watters ${ }^{1}$, Ronald Ruff ${ }^{1,2}$ \& Christina Weyer Jamora ${ }^{1,2}$ \\ ${ }^{1}$ San Francisco Clinical Neurosciences, San Francisco, USA \\ ${ }^{2}$ University of California, San Francisco, San Francisco, USA \\ Correspondence: Ronald Ruff, San Francisco Clinical Neurosciences, 909 Hyde Street, Suite 620, San Francisco, \\ CA 94109, USA. E-mail: ronruff@mindspring.com
}

Received: April 27, $2013 \quad$ Accepted: July 12, $2013 \quad$ Online Published: August 15, 2013

doi:10.5539/ijps.v5n3p182 URL: http://dx.doi.org/10.5539/ijps.v5n3p182

\begin{abstract}
This case study explores whether an individual can sustain Posttraumatic Stress Disorder (PTSD) subsequent to witnessing serious injury to his companion pet. While walking his dog, a 62 year old man was struck by a car. While lying on the road, he was emotionally traumatized by the serious injury to his companion pet dog. Later, he experienced significant flashbacks of his dog being injured, hypervigilance, avoidance of the injury site and leaving his house, and fear that his dog would be reinjured among other symptoms. The case study is analyzed relative to the Diagnostic Statistical Manual of Mental Disorders, $4^{\text {th }}$ edition (DSM-IV-TR) diagnostic criteria for PTSD. Currently the DSM-IV-TR limits the PTSD diagnostic Criteria A to people only, using a specific requirement that the traumatic injury take place to a "self" or "others" (American Psychiatric Association, 2000). This case study suggests an expansion of the PTSD's Criteria A to include additional stressor events, such as traumatic injury or death of a companion pet.
\end{abstract}

Keywords: PTSD, trauma, companion pet, dog, grief, loss, mild traumatic brain injury, neuropsychology

\section{Introduction}

Posttraumatic Stress Disorder (PTSD) was initially conceptualized during the 1970s and later included in the Diagnostic and Statistical Manual of Mental Disorders, $3^{\text {rd }}$ edition (DSM-III; American Psychiatric Association, 1980). The DSM-III's diagnostic criteria for PTSD weregeneral and unspecific, requiring that the event be universally distressing and unusual to most people's life experience (1980). With the release of the DSM-IV and the DSM-IV-TR, the diagnostic CriteriaA were refined to include a list of qualifying traumatic events that could cause PTSD. Criteria A requires the traumatic event be "a threatened or actual death or serious injury to the self or others" (American Psychiatric Association, 2000). It further requires that the stressor lead to impairment in multiple areas of a person's social and/or occupational functioning (2000).

Initially, PTSD was borne out of the need to describe the harmful psychological and physiological symptoms of veterans returning from the Vietnam War. Despite its narrow origin in war trauma, PTSD was later applied to a wider range of individuals exposed to trauma including but not limited to accidents, natural disasters, childhood abuse, domestic violence, rape, and assault. A consistent factor in the aforementioned examples of trauma is that loss or threat of loss is strictly reserved for human beings, at the exclusion of other living beings such as companion pets. This human requirement stems from the DSM-IV-TR diagnostic entry criteria for PTSD, which defines the victim as a person who has experienced the traumatic event (American Psychiatric Association, 2000). It further emphasizes the human requirement in stating that actual or threatened death must occur to "self" or "others". This definition precludes other living beings such companion pets.

Companion pets occupy a significant role in American society. With approximately $60 \%$ of households owning companion pets, a 2003/2004 Annual National Pet Owners Survey estimates there are more pets than people in the United States (Hall, Ng, Ursano, Holloway, Fullerton, \& Casper, 2004). The emotional bond developed between owners and their pets is strong, with most viewing their pets as members of their family (Cohen, 2002). Pets are also credited with improving both the mental and physical health of their owners. Several studies have confirmed the positive physical benefits pets bring to patients by reducing the risks of coronary heart and cardiovascular disease (Morley \&Fook, 2005). 
Offering emotional benefits of companionship, affection, and unconditional love, pets provide their owners increased security and well-being (Brown, Richards, \& Wilson, 1996). Pets are also credited with increasing trust and decreasing occurrences of depression and anxiety (Morley \& Fook, 2005). It has further been postulated that owners who lose pets may suffer distress and bereavement similar to losing a family member (Brown et al., 1996).

While significant research exists on the benefits of companion pets, very few studies have explored the psychological sequelae of actual or threatened companion pet loss and the relationship to PTSD. Forced abandonment and/or loss of a pet during a natural disaster were found to increase the risk of acute stress and PTSD while controlling for loss of home (Hunt, Al-Awadi, \& Johnson, 2008). In one study, 65 predominantly Caucasian female pet owners who survived Hurricane Katrina were evaluated for signs and symptoms of psychological distress. Results showed that pet loss was a significant predictor of acute stress, peri-traumatic dissociation, and PTSD symptom severity (Hunt et al., 2008). In contrast, death of a companion pet was found to cause significant symptoms of grief in owners due to attachment but rarely severe psychopathological reactions such as PTSD (Adrian, Deliramich, \& Frueh, 2009). In this study, 106 participants, survivors of pet loss, were recruited at a veterinarian clinic. Results showed most owners of deceased pets experienced common signs of grief and bereavement but lacked more severe pathology such as PTSD (Adrian et al., 2009). A factor that may have obviated the experience of traumatic symptoms was that over $50 \%$ of participants lost their pets to natural causes versus traumatic loss. In fact, traumatic loss or injury to an animal was not indicated and researched in the study.

Based on the paucity of research on the relationship between psychological sequelae and companion pet loss, this case study explores the question: Can one experience PTSD symptoms following a traumatic event to a belovedcompanion pet? Furthermore, this case study raises questions regarding limitations of the DSM-IV-TR's use of a human requirement as "person", "self", and "other", in the PTSD diagnostic Criteria A.

\section{Case Study}

A 62 year old Caucasian gentleman was referred for neuropsychological and psychological testing following an automobile accident. The case study was conducted through a review of the medical records, two clinical interviews, behavioral observations, and comprehensive neuropsychological and psychological evaluations.

On May $8^{\text {th }}$ 2006, Mr. SDand his dog, a Basset Hound, were pedestrian victims of an automobile accident. The circumstances surrounding the accident were obtained in a clinical interview with Mr. SD and corroborated by a witness and paramedics. Thewitness reported to paramedics that Mr.Sd stepped into the crosswalk and was struck by an oncoming vehicle on the left side of his body. Following the blow, he fell to the ground and experienced a brief gap in memory

In our examination, Mr. Sd was able to recall the preceding event of commencing his routine of a midmorning walk with his dog. Although he has no memory of the impact, his next memory consisted of lying on the ground, feeling pain on the left side of his body. However, what stood out was "hearing my dog crying". Unable to see the dog and come to her aid, he felt great anxiety that she was seriously injured and recalled feeling more worried for her than himself. His anxiety continued to rise when a police officer informed him his dog was going to be sent to the animal shelter. This further compounded his fear of losing the dog. While the paramedic transported him to the hospital he recalls his extreme anxiety as to status of his dog.

Our neuropsychological examination was administered approximately one year post accident. The test scores documented that Mr. SD possessed superior intellectual abilities with scores placing him well above average in the areas of verbal and spatial processing, as well as attention, memory, learning, and executive functioning. Thus, from a cognitive perspective no significant deficits were found. Furthermore, he was able to independently manage his activities of daily living.

In striking contrast, Mr. SD emotional distress was quiet salient. Mr. SD reported feeling increased fear, vulnerability, and helplessnessspecificallysurrounding his companion dog. Furthermore, he reported feeling upset often, avoiding the location of the accident, and experiencing ongoing "flashbacks of hearing the dog crying and lying on the street helpless." To cope with his feelings of panic around automobiles, Mr. SD isolated himself and his companion dog at home, for long period of time following his accident.

Upon further exploration of Mr. SD's recent psychological history, Mr. SD informed us that his beloved dog had helped him cope with the loss of his partner whom had died of a terminal illness. During the last few months of his partner's life, Mr. SD adopted and cared for this dog (who was initially his partner's dog). Growing attached to his pet, he soon relied on her for support and companionship throughouthis grieving process. He 
acknowledged, "Emotionally, I could not have made it without her."

Psychological examination results corroborated Mr. SD's report of emotional distress. Clinically significant elevations were identified on his test results for the Ruff Neurobehavioral Inventory's (Ruff \& Hibbard, 2003) Posttraumatic Stress Disorder scale (PTSD Post Morbid T Score $=71$ versus Premorbid T Score $=56$ ) and the Millon Clinical Multiaxial Inventory-II's(Millon, Davis, \&Millon, 1997) Anxiety scale (Scale Score $=80$ ). Additional elevations on the MCMI-II were Dependent (Scale Score $=84$ ), Depressive (Scale Score $=79$ ), and Avoidant (Scale Score $=79$ ). This combination of Mr. SD's longstanding character traits may have also contributed to Mr. SD's vulnerability to PTSD symptoms.

To further explore the symptoms of PTSD, a post-test follow-up clinical interview with Mr. SD was conducted. Through behavioral observations and specific signs and symptoms of trauma, a clear picture emerged that warranted the diagnosis of a PTSD, except the loss was neither the patient nor another person but his seriously injured companion dog.

The following analysis steps through the DSM-IV-TR's criteria for PTSD and juxtaposes it to Mr. SD's presentation and symptomatology. First, to meet the DSM-IV-TR's diagnostic criteria for PTSD a person must experience a traumatic event involving actual or threatened death or serious injury to self or others (American Psychiatric Association, 2000). The person must also react with overwhelming fear or helplessness (2000). Both Mr. SD and his dog endured an automobile accident that involved serious injury and threatened death. However, Mr. SD denied fears or even thoughts that he was going to die. Rather he worried that "his dog was seriously hurt" based on hearing its "loud" and "close" crying sounds. Furthermore, he reported feeling helpless due to being unable to assess his dog's status following the accident.

As to the second diagnostic criterion, the person must re-experience the trauma in one or more ways, such as flashbacks, dreams, or intense psychological distress among others listed in the DSM-IV-TR (American Psychiatric Association, 2000). Mr. SD was re-experiencing the traumatic event in the form of "flashbacks" of "lying helpless on the street" and feeling a "great deal upset" at being unable to "help his dog." Upon sharing this experience with the neuropsychologist, he also exhibited signs of intense psychological distress in the form of tearfulness and crying openly as he was recalling the threatened loss of his companion dog.

Third, the person must deliberately avoid circumstances surrounding the trauma and experience numbing of responsein three or more ways (American Psychiatric Association, 2000). Mr. SD avoided the location of the accident, felt his future was foreshortened, and had reduced interest in taking his dog for a walk, which he had previously enjoyed. He also exhibited signs of numbing with feeling "unbalanced, light headed, and less able to get out of the way" if confronted by a vehicle especially if he was walking his dog who had recovered. He communicated fears that he would be unable to move quickly or agilely enough to avoid he and his dog being struck again.

Fourth, the person must experience persistent symptoms of increased arousal (American Psychiatric Association, 2000).Mr. SD reported sleep disruptions, panic and hypervigilence since the accident. He tended to feel unsafe out of the home, and overwhelmed and anxious when confronted with automobile traffic both as a pedestrian and when traveling in a vehicle.

Fifth, criteria and symptoms must be present for greater than one month and cause clinically significant distress or impairment in social, occupational or other important areas of functioning (American Psychiatric Association, 2000). At the time of the assessment, Mr. SD had been experiencing intense symptoms of PTSD for more than 1 year. His anxiety and flashbacks fueled his isolation, which negatively impacted his social relationships.

\section{Discussion}

Mr. SD's symptoms, behavioral observations, and test results pointed to a diagnosis of PTSD, however, we were unable to render this diagnosis based on the DSM-IV-TR's diagnostic entry Criteria A of a threat to "self" or "others" (American Psychiatric Association, 2000). Mr. SD repeatedly stated that he never feared that his own life being threatened in the accident, yet he intensely feared for the life of his dog. The fear for his dog's life was characterized by ongoing hypervigilence, avoiding the scene of the injury, flashbacks, and feeling emotionally numb. Nevertheless, the persistence of Mr. SD's trauma symptoms, suggest he was quite traumatized by the injury to his pet and this threatened loss was consistent with PTSD.

This case study suggests the DSM-IV-TR's limited application of victimhood to humans and in our opinion warrants consideration for expanding the criteria to include companion pets for which there is a strong emotional attachment. The recommendation to expand the diagnostic criteria for PTSD is not a new one. Kilpatrick, Resnick, \&Acierno (2009) argued the importance of reconsidering Criteria A to ensure an accurate and 
comprehensive diagnosis. Specifically, they recommend that Criteria A be retained; however, with a statement indicating the "list of events is not exhaustive" and other stressors not stated may also lead to PTSD (Kilpatrick, Resnick, \&Acierno, 2009, p. 381; North, Suris, Davis, \& Smith, 2009). This addition would provide the flexibility to capture people who have symptoms to warrant services yet do not meet the DSM-IV-TR's Criteria A (American Psychiatric Association, 2000).

Mr. SD's strong emotional attachment to his companion pet was a central feature in this case. The emotional connection with this dog was strong because Mr. SD and his partner had been living with this dog for many years. His affection for the dog likely intensified when his partner died and asked him to "take good care of my dog." Not only did he promise his partner to do so, this companion dog may have represented a transitional object, one of the few remaining living connections he had to his deceased partner. Mr. SD's statements such as "emotionally, I could not have made it without her," are suggestive of Winnicott's concept of transitional object phenomena in terms of using symbols to buffer the stress between one's inner and external worlds (Winnicott, 1971).

"Loss throws the inner world of the sufferer into turmoil" (Holmes, 1993, p. 93). A transitional object such as a companion pet can help to provide a predictable harbor of safety as someone makes his or her way from one life phase to the next. It also helps to augment feelings of personal control and continuity of the self. Although, Mr. SD's loss of his partner was sad, it was expected due to his terminal longstanding illness. Thus, the death of the partner resulted in grief but did not cause a PTSD. Yet while grieving, the bond with the partner's dog was enhanced, the accident and treat to his dog did in fact elicit sufficient post-traumatic symptoms to warrant a diagnosis of PTSD, except for the fact that the injury was inflicted on his pet and not a person. Thus, the potential traumatic loss of this dog did represent a bond that is arguable of similar intensity a person has for if a friend is seriously harmed.

Even though Mr. SD was not given a formal diagnosis of PTSD, the treatment recommendations included psychotherapy for the treatment of his symptoms. Mr. SD represents an example of an individual who PTSD after he sustained a concussion. It is also noteworthy that Mr. SD did not develop a post-concussional disorder, but regretfully the PTSD persisted at a pronounced level. In sum, as to the question - can one develop PTSD from witnessing a trauma to a pet companion - our case seems to support this occurrence.

\section{References}

Adrian, J. A. L., Deliramich, A. N., \& Frueh, B. C. (2009). Complicated grief and Posttraumatic Stress Disorder in humans' response to death of pets/animals. Bulletin of The Menninger Clinic, 73, 176-187. http://dx.doi.org/10.1521/bumc.2009.73.3.176

American Psychiatric Association. (1980). Diagnostic and Statistical Manual of Mental Disorders (3rd ed.). Washington, DC: American Psychiatric Association.

American Psychiatric Association. (2000). Diagnostic and Statistical Manual of Mental Disorders (4th, text revision ed.). Washington, DC: American Psychiatric Association. http://dx.doi.org/10.1176/appi.books.9780890423349

Brown, B. H., Richards, H. C., \& Wilson, C. A. (1996). Pet bonding and pet bereavement among adolescents. $\begin{array}{lllll}\text { Journal of Counseling and Development, } & 74, & \text { 505-509. }\end{array}$ http://dx.doi.org/10.1002/j.1556-6676.1996.tb01901.x

Cohen, S. P. (2002). Can pets function as family members. Western Journal of Nursing Research, 24, 621-638. http://dx.doi.org/10.1177/019394502320555386

Hall, M. J., Ng, A., Ursano, R. J., Holloway, H., Fullerton, C., \& Casper, J. (2004). Psychological impact of the animal-human bond in disaster preparedness and response. Journal of Psychiatric Practice, 10, 368-374. http://dx.doi.org/10.1097/00131746-200411000-00005

Holmes, J. (1993). John Bowlby and attachment theory. Routledge: New York.

Hunt, M., Al-Awadi, H., \& Johnson, M. (2008). Psychological sequelae of pet loss following hurricane Katrina. Anthrozoos, 21,109-121. http://dx.doi.org/10.2752/175303708X305765 27

Kilpatrick, D. G., Resnick, H. S., \& Acierno, R. (2009). Should PTSD criterion a be retained? Journal of Traumatic Stress, 22, 374-383. http://dx.doi.org/10.1002/jts.20436 27

Millon, T., Davis, R. D., \& Millon, C. (1997). Millon Clinical Muiltiaxial Iventory-II Manual (2nd ed.). Minneapolis, MN: National Computer Systems. 
Morley, C., \& Fook, J. (2005). The importance of pet loss and some implications for services. Mortality, 10, 127-143. http://dx.doi.org/10.1080/13576270412331329849

North, C. S., Suris, A. M., Davis, M., \& Smith, R. P. (2009). Toward validation of the diagnosis of Posttraumatic Stress Disorder. American Journal of Psychiatry, 166, 34-41. http://dx.doi.org/10.1176/appi.ajp.2008.08050644

Rowan, A. N., \& Beck, A. M. (1994). The health benefits of human-animal interactions. Anthroos, 2, 85-98.27

Ruff, R. M., \& Hibbard, K. M. (2003). Ruff Neurobehavioral Inventory. Odessa, FL: Psychological Assessment Resources.

Sbordone, R. J., \& Ruff, R. M. (2010) Re-examination of the controversial coexistence of traumatic brain injury and posttraumatic stress disorder: Misdiagnosis and self-report measures. Psychological Injury and Law, 3, 63-76. http://dx.doi.org/10.1007/s12207-010-9066-z

Winnicott, D. W. (1971). Playing and Reality. London: Routeledge.

\section{Copyrights}

Copyright for this article is retained by the author(s), with first publication rights granted to the journal.

This is an open-access article distributed under the terms and conditions of the Creative Commons Attribution license (http://creativecommons.org/licenses/by/3.0/). 